\title{
An Empirical Growth Model for Major Oil Exporters
}

Hadi Salehi Esfahani, Kamiar Mohaddes, and M. Hashem Pesaran

March 2012

CWPE 1215 


\title{
An Empirical Growth Model for Major Oil Exporters*
}

\author{
Hadi Salehi Esfahani ${ }^{\mathrm{a}}$, Kamiar Mohaddes ${ }^{\mathrm{b} \dagger}$, and M. Hashem Pesaran ${ }^{\mathrm{bc}}$ \\ a Department of Economics, University of Illinois \\ b Faculty of Economics, University of Cambridge \\ c Department of Economics, University of Southern California
}

March 10, 2012

\begin{abstract}
This paper develops a long-run growth model for a major oil exporting economy and derives conditions under which oil revenues are likely to have a lasting impact. This approach contrasts with the standard literature on the "Dutch disease" and the "resource curse", which primarily focuses on short-run implications of a temporary resource discovery. Under certain regularity conditions and assuming a Cobb-Douglas production function, it is shown that $(\log )$ oil exports enter the long-run output equation with a coefficient equal to the share of capital $(\alpha)$. The long-run theory is tested using quarterly data on nine major oil economies, six of which are current members of OPEC (Iran, Kuwait, Libya, Nigeria, Saudi Arabia, and Venezuela), plus Indonesia which is a former member, and Mexico and Norway, which are members of the OECD. Overall, the test results support the long-run theory. The existence of long-run relations between real output, foreign output and real oil income is established for six of the nine economies considered. The exceptions, Mexico and Norway, do not possess sufficient oil reserves for oil income to have lasting impacts on their economies. At their current production rates, the proven oil reserves of Mexico and Norway are expected to last 9 and 10 years respectively, as compared to reserve-production ratios of OPEC members, which lie in the range of 45 to 125 years. For Indonesia, whose share of oil income in GDP has been declining steadily over the past three decades, the theory suggests that the effect of oil income on the economy's steady state growth rate will vanish eventually, and this is indeed confirmed by the results. Sensible estimates of $\alpha$ are also obtained across the six economies with long-run output equations, and impulse responses are provided for the effects of shocks to oil income and foreign output in these economies.
\end{abstract}

JEL Classifications: C32, C53, E17, F43, F47, Q32.

Keywords: Growth models, long run and error correcting relations, major oil exporters, OPEC member countries, oil exports and foreign output shocks.

${ }^{*}$ We are grateful to conference participants at the University of Illinois at Urbana-Champaign, the University of Southern California, and the Dubai School of Government for constructive comments. We would also like to thank the Co-editor (Herman van Dijk) and two anonymous referees for most helpful suggestions.

${ }^{\dagger}$ Corresponding author. Email address: km418@cam.ac.uk. 


\section{Introduction}

In this paper we develop a long-run output relation for a major oil exporting economy where oil income to output ratio is expected to remain high over a prolonged period. The focus of this analysis differs from that of the "Dutch disease" and "resource curse" literature that considers the revenues from the resource to be intrinsically temporary and focuses on the relatively short-term implications of the resource discovery. See Corden and Neary (1982), Krugman (1987), Neary and van Wijnbergen (1986), and van der Ploeg and Venables (2009) for a recent survey. We extend the stochastic growth model developed in Binder and Pesaran (1999) to allow for the possibility that a certain fraction of oil export revenues is invested in the domestic economy. We distinguish between the two cases where the growth of oil income, $g^{0}$, is less than the natural growth rate (the sum of the population growth, $n$, and the growth of technical progress, $g$ ), and when $g^{0} \geq g+n$. Under the former, the effects of oil income on the economy's steady growth rate will vanish eventually, whilst under the latter, oil income enters the long-run output equation with a coefficient which is equal to the share of capital $(\alpha)$ if it is further assumed that the underlying production technology can be represented by a Cobb-Douglas production function.

The empirical validity of the long-run theory is tested on eight large oil economies, with a variety of development experiences and political systems, showing that the long-run output equation derived in the paper applies equally to OPEC (Iran, Kuwait, Libya, Nigeria, Saudi Arabia, and Venezuela) and OECD (Mexico and Norway) oil exporters. The long-run output equation is tested and estimated using cointegration analysis by incorporating the theoryconsistent long-run output equation within a vector autoregressive error correction model augmented with a foreign output variable. The inclusion of the foreign output variable allows us to separate the long-run effects of global technological developments from the (possible) long-run impacts of oil income.

The test results and the estimates obtained support the theory and the existence of a long-run relation between real domestic output, real oil income and real foreign output (all measured in terms of domestic currency) for six of the eight economies considered. The exceptions, Mexico and Norway, do not possess sufficient oil reserves for their oil income to have lasting impacts on their steady state output growths. Although Mexico and Norway are currently amongst the major oil exporters, their proven oil reserves are low compared to the other major oil exporters. At their current production rates, the proven oil reserves of Mexico and Norway are expected to last 9 and 10 years respectively, compared to the reserve-production ratios of the six OPEC oil producers considered in this paper, which lie in the range of 45 years (for Nigeria) to 125 years (for Venezuela).

Using the long-run output equations, we also obtain sensible estimates of $\alpha$ across the six major oil exporters. The point estimates of $\alpha$ for these economies fall in the range of 0.11 to 0.18 , except for Nigeria where $\alpha$ is very poorly estimated. These estimates are lower than the values of $0.30-0.35$ used in calibration studies of advanced economies, but are in line with the estimates reported in a number of empirical studies in the literature that include developing and oil-exporting economies. See, for instance, Pedroni (2007) and Cavalcanti et al. (2011a). In addition, we find that with the exception of Libya, the major oil economies considered have experienced rates of technological progress that are comparable to those of their major trading partners over the past three decades. 
Moreover, we estimate a VARX* model for Indonesia, a former OPEC member which has seen its share of oil exports revenue in GDP declining over the past three decades, and for which $g^{0}<g+n$. In the case of Indonesia, the theory predicts that out of the two drivers of growth, only technology should have a significant long-run impact on real output, and indeed we find that in the estimated long-run output equation for Indonesia only the foreign output variable is statistically significant. Real oil income does not seem to exert any significant effect on real output in the long run; thus providing corroborative evidence on the validity of the long-run output equation developed in this paper.

Finally, we examine the speed of response of the major oil exporters to shocks using persistence profiles that consider the effects of system-wide shocks on the cointegrating output equations and the generalized impulse response functions (GIRFs) for the analysis of the effects of shocks to oil exports and foreign output on real output in major oil exporters. It is found that shocks have permanent effects on real output and tend to diffuse relatively rapidly, within 2-3 years in most cases, which is much faster than the estimates obtained for advanced economies.

The rest of the paper is set out as follows. Section 2 develops a long run macroeconomic model for an oil exporting economy and discusses the long-run restrictions applicable to oil exporters. Section 3 describes the VARX* econometric model that embodies the long run relation and considers the estimates of the output equation for major oil exporters. The GIRFs of the effects of shocks to oil exports on output in the case of the major oil exporters are discussed in Section 4. Section 5 offers some concluding remarks.

\section{A Theory of Economic Growth for a Major Oil Ex- porter}

Most papers in the growth literature do not include natural resource abundant economies, in particular oil exporting countries, in their cross-country empirical analysis. Furthermore, the literature that specifically deals with resource abundant economies tends to treat revenues that flow from such resources as "intrinsically temporary", and only considers the short term effects. See, for example, van der Ploeg and Venables (2009). A number of early studies also considered the macroeconomic effects of the resource discovery and focussed on the "Dutch disease" phenomenon first experienced in Netherlands after the large, but short-lived, discovery of gas in 1960s. See, for example, Corden and Neary (1982), Krugman (1987), and Neary and van Wijnbergen (1986) among others.

The Dutch disease hypothesis postulates that an exogenous unexpected increase in foreign exchange revenues from the resource, due to rising prices or output, will result in real exchange rate appreciation and a fall in output and employment of the non-resource traded goods sector, often manufacturing. This by itself need not have adverse long run implications for the economy as a whole. One would expect the economy to re-adjust once the revenues from the resource are diminished or vanish altogether, unless there are important non-convexities or imperfections in the economy. For example, if the manufacturing sector is subject to economies of scale or learning by doing, the loss of manufacturing capacity will be very costly to reverse. 
The more recent literature on resource abundance and economic growth focusses on the political economy considerations and argues that large windfalls from the resource create incentives for rent-seeking activities that involve corruption (Mauro (1995) and Leite and Weidmann (1999)), voracity (Lane and Tornell (1996) and Tornell and Lane (1999)), and possibly civil conflicts (Collier and Hoeffler (2004)). ${ }^{1}$ Some of these considerations have been recently formalized by Caselli and Cunningham (2009) where they attempt to characterize conditions under which an increase in the size of the resource rent leads to a decrease in real output, the so called "natural resource curse" hypothesis. Empirical support for this hypothesis was originally provided by Sachs and Warner (1995) who showed the existence of a negative relationship between real GDP growth per capita and different measures of resource abundance, such as the ratio of resource exports to GDP. The finding that resource rich countries tend to perform poorly when compared to economies that are not well endowed with natural resources is clearly paradoxical and require further explanations and naturally has led to a growing empirical literature.

Most papers in the resource curse literature tend to follow Sachs and Warner's crosssectional specification introducing new explanatory variables, while others derive theoretical models that are loosely related to their empirical specification. Some of these papers confirm Sachs and Warner's results, but there is an emerging literature, including Brunnschweiler and Bulte (2008), Cavalcanti et al. (2011a), and Cavalcanti et al. (2011b), which argues that the so-called resource curse paradox does not exist, and that while resource dependence does not affect growth, resource abundance in fact positively affects growth. ${ }^{2}$ Thus, from the empirical literature, there is no clear cut answer to whether natural resource abundance is a blessing or a curse. The recent theoretical work of Caselli and Cunningham (2009) is not conclusive either and, perhaps not surprisingly, can yield outcomes that are not compatible with the resource curse hypothesis.

While in the short run we would expect that an increase in oil export revenues would put pressure on the real exchange rate, the Dutch disease channel will only harm an economy in the long run if these oil revenues are short-lived or subject to such volatility that in some periods oil export revenues are negligible while in other periods they are prominent. For major oil exporting countries, of which many started oil extraction and exports in the beginning of the 20th century, the reserve-to-extraction ratio indicates that they are capable of producing for many more decades even in the absence of new oil field discoveries or major advances in oil exploration and extraction technologies.

Although it is true that natural resources are ultimately exhaustible, for the purpose of macroeconomic analysis over the medium term it is more realistic to view such resources as permanent. For example, in the case of Iran despite a 100 years history of exploration and production, Iran's current estimated reserve-to-extraction ratio suggests a further 87 years of oil production. In addition, Iran has the second largest natural gas reserves after Russia, around 60 percent of which is yet to be developed. ${ }^{3}$ Although it is clear that Iran's oil and gas reserves will be exhausted eventually, this is likely to take place over a relatively

\footnotetext{
${ }^{1}$ For early contributions on the importance of rent seeking in oil exporting economies see Mahdavi (1970) and Pesaran (1982)

${ }^{2}$ In a recent paper, Cavalcanti et al. (2012) argue that it is the volatility of commodity prices rather than abundance per se, that drives the "resource curse" paradox.

${ }^{3}$ See, for example, Amuzegar (2008) and the British Petroleum Statistical Review of World Energy.
} 
Figure 1: Oil Export Revenues to Income Ratios for Major Oil Exporters

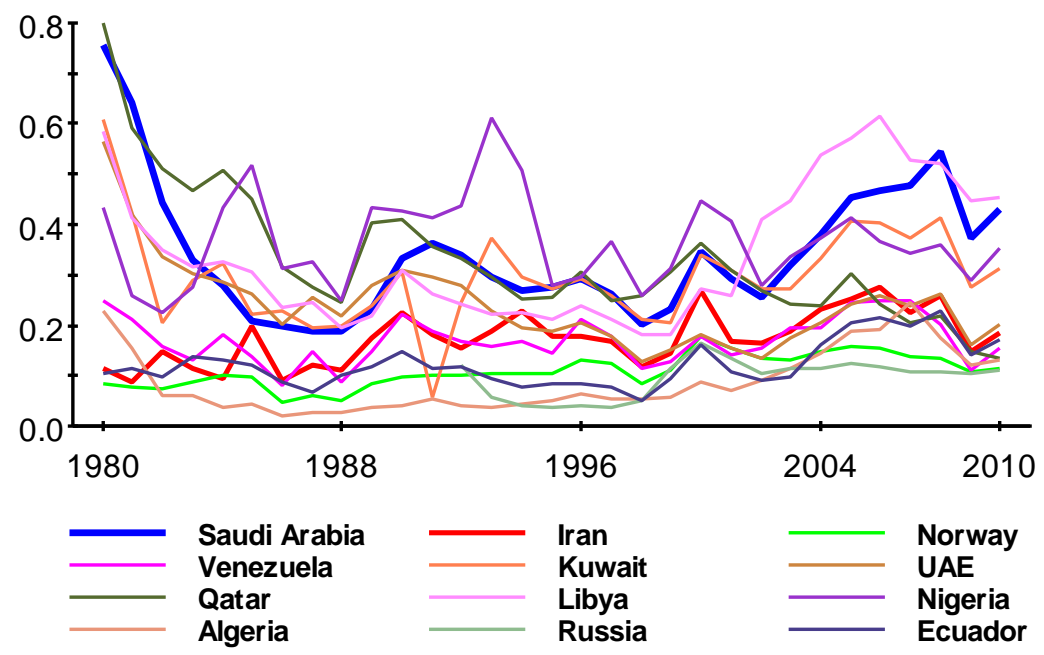

Source: GDP data is from the IMF International Financial Statistics and oil export data is from OPEC Annual Statistical Bulletin.

long period. Of course, Iran is not unique in this regard. As Figure 1 shows most other OPEC (Organization of the Petroleum Exporting Countries) member countries such as Saudi Arabia, Venezuela, Nigeria, Algeria, United Arab Emirates and Kuwait, and a few countries outside OPEC such as Norway and Russia have similar oil income GDP ratios that have remained relatively stable over time. Therefore, there is little evidence to suggest that in these economies oil income will be diminishing any time soon.

To summarize, most macroeconomic analysis of oil revenues tend to take a short-term perspective. They usually focus on the effects of oil revenues on the real exchange rate (Dutch disease) and government budget expansion, thus failing to consider the effects of oil revenues on long-run growth. This approach makes sense for countries with a limited amount of oil reserves, but not for major oil exporting countries such as Iran and Saudi Arabia. Therefore, the aim of the next sub-section is to develop a long-run theory for oil exporters in which oil export revenues affect the growth rate of income in the long run. In this process rent-seeking and other political economy considerations are clearly still important, and tend to manifest themselves in the equilibrium level of capital stock and can influence the steady state growth of the economy. However, such political economy considerations will not be addressed in this paper. 


\subsection{Long-run Output Equation for Oil Exporting Economies}

Consider an oil exporting economy with a constant return to scale production function in labour, $L_{t}$, and capital stock, $K_{t}$ :

$$
Y_{t}=A_{t} L_{t} f\left(\frac{K_{t}}{A_{t} L_{t}}\right),
$$

where $Y_{t}$ is the real output, and $A_{t}$ is an index of labour augmented technological progress. Following the literature, it will be assumed that $A_{t}$ and $L_{t}$ are exogenously given and follow general linear processes defined by

$$
\ln \left(A_{t}\right)=a_{0}+g t+u_{a t}
$$

and

$$
\ln \left(L_{t}\right)=l_{0}+n t+u_{l t} .
$$

where $a_{0}$ and $l_{0}$ are economy-specific initial endowments of technology and labour, $g$ and $n$ are the steady state growth rates of technology and labour input respectively, and $u_{a t}$ and $u_{l t}$ follow general linear processes possibly with unit roots.

Denote by $X_{t}$ the real value of (net) oil exports

$$
X_{t}=\frac{E_{t} P_{t}^{o} X_{t}^{o}}{P_{t}}
$$

where $P_{t}^{o}$ is the price of oil per barrel in US dollar, $X_{t}^{o}$ is the total number of barrels of oil exports, $E_{t}$ is the exchange rate in terms of US dollar, and $P_{t}$ is the consumer price index. Note that we could also include oil as an input in the production process but we abstract from this to simplify the analysis. Let $\kappa_{t}$ be the value of capital in terms of effective labour input:

$$
\kappa_{t}=\frac{K_{t}}{A_{t} L_{t}}
$$

and $\chi_{t}$ denote the value of real oil exports in terms of effective units of labour input:

$$
\chi_{t}=\frac{X_{t}}{A_{t} L_{t}}
$$

Then the capital accumulation equation can be written as

$$
K_{t+1}=(1-\delta) K_{t}+s\left(\boldsymbol{\zeta}_{t}\right) Y_{t}+\lambda\left(\boldsymbol{\zeta}_{t}\right) X_{t},
$$

where $\delta$ is the rate of depreciation $(0<\delta<1), s\left(\boldsymbol{\zeta}_{t}\right)$ and $\lambda\left(\boldsymbol{\zeta}_{t}\right)$ are the shares of nonoil output and (net) oil income that are invested, and $\boldsymbol{\zeta}_{t}=\left(\kappa_{t}, \chi_{t}\right)^{\prime}$ is the vector of state variables. It is assumed that $s\left(\boldsymbol{\zeta}_{t}\right)$ and $\lambda\left(\boldsymbol{\zeta}_{t}\right)$ lie in the range $(0,1)$, and that oil is produced without the use of domestic resources.

Using (2) and (3), the general specification for $\ln \left(A_{t} L_{t}\right)$ is given by:

$$
\ln \left(A_{t} L_{t}\right)=a_{0}+l_{0}+(g+n) t+u_{t}
$$


where $u_{t}=u_{a t}+u_{l t}$. Hence

$$
\Delta \ln \left(A_{t+1} L_{t+1}\right)=g+n+\Delta u_{t+1}
$$

Using (8) we can write the capital accumulation equation given in (7) in terms of effective labour units:

$$
\kappa_{t+1}=\left[(1-\delta) \kappa_{t}+s\left(\boldsymbol{\zeta}_{t}\right) f\left(\kappa_{t}\right)+\lambda\left(\boldsymbol{\zeta}_{t}\right) \chi_{t}\right] \exp \left(-g-n-\Delta u_{t+1}\right) .
$$

Note that $\Delta u_{t+1}$ is a stationary process irrespective of whether the processes for $A_{t}$ or $L_{t}$ have unit roots. The presence of a unit root in $A_{t}$ is, however, essential if log per capita output is to have a unit root, a hypothesis that cannot be rejected when tested using historical output series.

To solve for $\kappa_{t}$, the process for real oil revenues must also be specified. Given that oil revenues are dominated by oil price movements and the latter is best approximated by a random walk model with a drift, we assume that

$$
\Delta \ln \left(X_{t+1}\right)=g^{o}+\Delta v_{t+1}
$$

where $g^{o}$ is the drift coefficient, and $v_{t} \sim \operatorname{iid}\left(0, \sigma_{v}^{2}\right)$. Given (8) and (10) we have:

$$
\begin{aligned}
\Delta \ln \left(\chi_{t+1}\right) & =g^{o}+\Delta v_{t+1}-\left(g+n+\Delta u_{t+1}\right) \\
& =g^{o}-g-n+\Delta v_{t+1}-\Delta u_{t+1} .
\end{aligned}
$$

The possibility of a long run impact from oil income to per capita output depends on the growth of oil income $\left(g^{o}\right)$ relative to the combined growth of labour and technology. In the case where $g^{o}<g+n, \chi_{t} \rightarrow 0$ as $t \rightarrow \infty$, and the importance of oil income in the economy will tend towards zero in the limit and the standard growth model will become applicable. In this case oil income is neither a blessing nor a curse in the long run. This is as to be expected since with oil income rising but at a slower pace than the growth of real output, the share of oil income in aggregate output eventually tends towards zero. Therefore, a resource could be non-depletable but still have no long-run impacts.

But if $g^{o} \geq g+n$, oil income continues to exert an independent impact on the process of capital accumulation even in the long run. Under this case $\chi_{t} \neq 0$ for all $t$, and scaling (9) by $\chi_{t}$ we obtain:

$$
\frac{\kappa_{t+1}}{\chi_{t+1}}=\left[(1-\delta) \frac{\kappa_{t}}{\chi_{t}}+s\left(\boldsymbol{\zeta}_{t}\right) \frac{f\left(\kappa_{t}\right)}{\chi_{t}}+\lambda\left(\boldsymbol{\zeta}_{t}\right)\right] \exp \left(-g-n-\Delta u_{t+1}\right) \exp \left(-\Delta \ln \chi_{t+1}\right) .
$$

Denoting the scaled variables by $\sim$ such that $\widetilde{z}_{t}=z_{t} / \chi_{t}$, and using (11) we then have

$$
\widetilde{\kappa}_{t+1}=\left[(1-\delta) \widetilde{\kappa}_{t}+s\left(\boldsymbol{\zeta}_{t}\right) \widetilde{y}_{t}+\lambda\left(\boldsymbol{\zeta}_{t}\right)\right] \exp \left(-g^{o}-\Delta v_{t+1}\right)
$$

where $\widetilde{y}_{t}=y_{t} / \chi_{t}=f\left(\kappa_{t}\right) / \chi_{t}$. In the case of a Cobb-Douglas production function, $f\left(\kappa_{t}\right)=\kappa_{t}^{\alpha}$, where $0<\alpha<1$ is the share of capital, we have

$$
\widetilde{\kappa}_{t+1}=\left[(1-\delta) \widetilde{\kappa}_{t}+\check{s}\left(\boldsymbol{\zeta}_{t}\right) \tilde{\kappa}_{t}^{\alpha}+\lambda\left(\boldsymbol{\zeta}_{t}\right)\right] \exp \left(-g^{o}-\Delta v_{t+1}\right) \text {, }
$$


where $\check{s}\left(\boldsymbol{\zeta}_{t}\right)=s\left(\boldsymbol{\zeta}_{t}\right) / \chi_{t}^{1-\alpha}=s\left(\boldsymbol{\zeta}_{t}\right) \chi_{0}^{-(1-\alpha)} e^{-(1-\alpha)\left(g^{o}-g-n\right) t-(1-\alpha)\left(v_{t}-u_{t}\right)}$. We need now to consider the cases where $g^{o}>g+n$, and $g^{o}=g+n$, separately. Under the former and since $1-\alpha>0$, and $s\left(\boldsymbol{\zeta}_{t}\right)$ is bounded in $\boldsymbol{\zeta}_{t}$, then $\lim _{t \rightarrow \infty} \check{s}\left(\boldsymbol{\zeta}_{t}\right)=0$, and for sufficiently large $t(13)$ behaves as

$$
\widetilde{\kappa}_{t+1}=\left[(1-\delta) \widetilde{\kappa}_{t}+\lambda\left(\boldsymbol{\zeta}_{t}\right)\right] \exp \left(-g^{o}-\Delta v_{t+1}\right),
$$

and $\tilde{\kappa}_{\infty}=\lim _{t \rightarrow \infty} \widetilde{\kappa}_{t}$ will exits so long as $E\left[(1-\delta) \exp \left(-g^{o}-\Delta v_{t+1}\right)\right]<1$. In the case where $v_{t}$ is normally distributed this condition can be written as $g^{o}>\sigma_{v}^{2}+\ln (1-\delta)$, and will be satisfied if growth of oil income is not too volatile. Based on historical data on real oil prices, $\sigma_{v}$ is around 20 per cent per annum, and taking $\delta=0.05$ we would then need that $g^{o}>0.04-0.0513$ which is clearly met in practice.

In the knife-edge case where $g^{o}=g+n$, the limiting distribution of $\widetilde{\kappa}_{t}$ will be the function of both saving rates (savings out of domestic output and oil income) and will be ergodic only if certain regularity conditions on $\check{s}\left(\boldsymbol{\zeta}_{t}\right) / \widetilde{\kappa}_{t}$ and $\lambda\left(\boldsymbol{\zeta}_{t}\right) / \widetilde{\kappa}_{t}$ are met. Note that in the present case $\check{s}\left(\boldsymbol{\zeta}_{t}\right)=s\left(\boldsymbol{\zeta}_{t}\right) \chi_{0}^{-(1-\alpha)} e^{-(1-\alpha)\left(v_{t}-u_{t}\right)}$. Following Binder and Pesaran (1999), and assuming that $\check{s}\left(\boldsymbol{\zeta}_{t}\right) / \widetilde{\kappa}_{t}$ and $\lambda\left(\boldsymbol{\zeta}_{t}\right) / \widetilde{\kappa}_{t}$ are monotonic in $\boldsymbol{\zeta}_{t}$ and that certain regularity conditions hold, then it can be shown that as $t \rightarrow \infty, \widetilde{\kappa}_{t+1} \rightarrow \tilde{\kappa}_{\infty}$, where $\tilde{\kappa}_{\infty}$ is a time-invariant random variable with a non-degenerate probability distribution function.

To summarize, subject to familiar regularity conditions, we have

$$
\ln \kappa_{t+1} \sim I(0), \text { if } g^{o}<g+n,
$$

and

$$
\ln \widetilde{\kappa}_{t+1}=\ln \kappa_{t+1}-\ln \chi_{t+1} \sim I(0), \text { if } g^{o} \geq g+n,
$$

where $I(0)$ represents a stationary (integrated of order 0 ) variable. Also since under a CobbDouglas production function

$$
\ln \kappa_{t}=\alpha^{-1}\left[\ln \left(Y_{t} / L_{t}\right)-\ln \left(A_{t}\right)\right]
$$

then in terms of per capita output we have

$$
\ln \left(Y_{t} / L_{t}\right)-\ln \left(A_{t}\right) \sim I(0), \text { if } g^{o}<g+n,
$$

and

$$
\ln \left(Y_{t} / L_{t}\right)-(1-\alpha) \ln A_{t}-\alpha \ln \left(X_{t} / L_{t}\right) \sim I(0), \text { if } g^{o} \geq g+n .
$$

Therefore, the issue of whether oil income is likely to have a lasting impact on per capita output growth can be tested by a cointegration analysis involving log per capita output, log of real per capita oil income and an index of technological progress. In such an empirical analysis it is important that $A_{t}$ can be measured independently of oil income. With this in mind and following Garratt et al. (2003) we assume that domestic technology evolves from a diffusion and adaptation of foreign technology denoted by $A_{t}^{*}$. Specifically we assume that

$$
\ln \left(A_{t}\right)=a_{0}^{*}+\theta \ln \left(A_{t}^{*}\right)+\eta_{t}
$$

where $\theta$ measures the extent to which foreign technology is diffused and adapted successfully by the domestic economy in the long run, $\eta_{t} \sim I(0)$ represents the transient differences 
between the levels of technological innovations, and $a_{0}^{*}$ is a fixed scaling factor. If $\theta<1$, this implies that the domestic technology is falling behind the rest of the world, while $\theta>$ 1 implies that the domestic technology is quickly catching up and outperforming foreign technological growth, while $\theta=1$ represents the case where domestic and foreign technology are assumed to grow at the same rate.

Denoting foreign capital stock in effective labour units by $\kappa_{t}^{*}$, and assuming that the production technology in the foreign economy also follows the Cobb-Douglas production function, $f^{*}\left(\kappa_{t}^{*}\right)=\left(\kappa_{t}^{*}\right)^{\alpha^{*}}$, where $\alpha^{*}$ is the share of capital in the foreign economy, we have

$$
\ln \left(Y_{t}^{*} / L_{t}^{*}\right)-\ln A_{t}^{*}=\alpha^{*} \ln \left(\kappa_{t}^{*}\right)
$$

Using a similar line of argument as above for an economy without oil it also follows that $\ln \left(\kappa_{t}^{*}\right) \sim I(0) .{ }^{4}$ Using this result in (20) and together with (19) now yields

$$
\ln \left(A_{t}\right)-\theta \ln \left(Y_{t}^{*} / L_{t}^{*}\right)=a_{0}^{*}-\theta \alpha^{*} \ln \left(\kappa_{t}^{*}\right)+\eta_{t} \sim I(0),
$$

which upon substitution in (17) and (18) gives the following long-run relations in observables

$$
\ln \left(Y_{t} / L_{t}\right)-\theta \ln \left(Y_{t}^{*} / L_{t}^{*}\right) \sim I(0), \text { if } g^{o}<g+n
$$

and

$$
\ln \left(Y_{t} / L_{t}\right)-\theta(1-\alpha) \ln \left(Y_{t}^{*} / L_{t}^{*}\right)-\alpha \ln \left(X_{t} / L_{t}\right) \sim I(0), \text { if } g^{o} \geq g+n .
$$

For the purpose of econometric modeling of the long-run interactions of real oil income with the other variables in the economy, it is convenient to decompose $\ln \left(X_{t} / L_{t}\right)$ as

$$
\ln \left(X_{t} / L_{t}\right)=\ln \left(E_{t} / P_{t}\right)+\ln \left(P_{t}^{o} X_{t}^{o} / L_{t}\right) .
$$

Using this in (22) now yields

$$
\ln \left(Y_{t} / L_{t}\right)-\theta(1-\alpha) \ln \left(Y_{t}^{*} / L_{t}^{*}\right)-\alpha \ln \left(E_{t} / P_{t}\right)-\alpha \ln \left(P_{t}^{o} X_{t}^{o} / L_{t}\right) \sim I(0) \text {, if } g^{o} \geq g+n \text {. }
$$

For empirical applications the analysis can be $\operatorname{simplified~if~} \ln \left(L_{t}\right)$ and $\ln \left(L_{t}^{*}\right)$ are trend stationary so that

$$
\ln \left(L_{t}\right)-n t \sim I(0) \text { and } \ln \left(L_{t}^{*}\right)-n^{*} t \sim I(0)
$$

where $n$ and $n^{*}$ are the labour force growth rates of the domestic and the world economy respectively. This allows for the possibility of both foreign and domestic demand shocks as long as they are temporary, or in other words $I(0)$. In this case the long-run output equations become

$$
\ln \left(Y_{t}\right)-\theta \ln \left(Y_{t}^{*}\right)-\left(n-\theta n^{*}\right) t \sim I(0), \text { if } g^{o}<g+n
$$

and

$$
\ln \left(Y_{t}\right)-\psi_{1} \ln \left(Y_{t}^{*}\right)-\psi_{2} \ln \left(E_{t} / P_{t}\right)-\psi_{3} \ln \left(P_{t}^{o} X_{t}^{o}\right)-\gamma_{y} t \sim I(0), \text { if } g^{o} \geq g+n,
$$

\footnotetext{
${ }^{4}$ The assumption that the foreign economy does not have oil can be relaxed by assuming that the growth of oil income in the foreign economy is less than its combined growth of labour and technology.
} 
where

$$
\psi_{1}=\theta\left(1-\psi_{2}\right), \psi_{2}=\psi_{3}=\alpha, \text { and } \gamma_{y}=(1-\alpha)\left(n-\theta n^{*}\right) .
$$

Equation (24) is sufficiently general and covers both cases where $g^{o}<g+n$ and $g^{o} \geq g+n$. Under the former $\psi_{1}=\theta, \psi_{2}=\psi_{3}=0$, whilst under the latter $\psi_{2}=\psi_{3} \neq 0$. This expanded formulation is also convenient for econometrics analysis as it distinguishes between the real exchange rate effect, $\ln \left(E_{t} / P_{t}\right)$, which is best treated as endogenous, and the logarithm of oil exports in US dollar, $\ln \left(P_{t}^{o} X_{t}^{o}\right)$, which for all practical purposes can be viewed as exogenous for estimation purposes.

The above formulation further allows us to test other hypotheses of interest concerning $\theta$ and $\gamma_{y}$. The value of $\theta$ provides information on the long-run diffusion of technology to the oil exporting economy. The diffusion of technology is at par with the rest of the world if $\theta=1$, whilst a value of $\theta$ below unity suggests inefficiency that prevents the adoption of best practice techniques, possibly due to rent-seeking activities. When $\theta=1$ steady state per capita output growth in the oil exporting economy can only exceed that of the rest of the world if oil income per capita is rising faster than the steady state per capita output in the rest of the world. The steady state output growth in the oil exporting economy could be lower than the rest of the world per capita output growth if $\theta<1$. In the case of most resource abundant economies, where $g^{o}<g+n$, their steady state growth rates cannot exceed that of the rest of the world unless $\theta>1$.

Finally, in the context of our theoretical derivations, it is important to note that the empirical literature which is based on cross-section regressions on initial levels of per capita income captures short-term deviations from the steady states and in view of the substantial heterogeneity that exists across countries can be quite misleading, particularly as far as identification of $\theta$ and inferences on management inefficiency of resource abundant economies are concerned.

\section{Empirical Applications to Major Oil Exporters}

In what follows we test the validity of the long-run output theory on a number of major oil exporters with varying levels of oil reserves, development experiences, and institutional qualities, and provide estimates of the structural parameters, $\alpha$ and $\theta$, implied by the long-run output equation (24). In particular, we consider six OPEC members, three of which are located in the Middle East (Iran, Kuwait and Saudi Arabia), one in Latin America (Venezuela), and a further two in Africa (Libya and Nigeria). These economies differ considerably from each other in terms of geographical location, population density, institutional quality, and the level of proven oil reserves, but have one important feature in common, namely that oil exports play a significant role in their economies, albeit with different degrees. See Table 1. For example, Saudi Arabia and Iran have the largest oil reserves in the world, but Saudi Arabia exports more than 2.7 times that of Iran. In addition, Saudi Arabia's revenues from oil exports to GDP ratio stood at $49.7 \%$ as compared to $25.3 \%$ in the case of Iran.

For comparison we shall also estimate long-run output equations for Mexico and Norway, the largest oil exporters amongst the OECD economies, and Indonesia a former OPEC 
Table 1: Oil Reserves, Production and Institutional Quality Index for Major Oil Exporters, averages over 2006-2008

\begin{tabular}{lccccc}
\hline Country & $\begin{array}{c}\text { Oil Reserves } \\
\text { (Billion Barrels) }\end{array}$ & $\begin{array}{c}\text { Oil Reserve- } \\
\text { Production Ratio } \\
\text { (Years) }\end{array}$ & $\begin{array}{c}\text { Oil Exports } \\
\text { (Million Barrels } \\
\text { per day) }\end{array}$ & $\begin{array}{c}\text { Oil Exports } \\
\text { Revenue-GDP } \\
\text { Ratio (\%) }\end{array}$ & $\begin{array}{c}\text { Polity Index } \\
{[-10,10]}\end{array}$ \\
\hline Indonesia & & 11.2 & 0.3 & 2.0 & 8 \\
Iran & 138.1 & 87.7 & 2.6 & 25.3 & -6 \\
Kuwait & 101.5 & 102.9 & 1.7 & 39.7 & -7 \\
Libya & 43.1 & 65.0 & 1.4 & 55.5 & -7 \\
Mexico & 12.3 & 9.8 & 1.7 & 4.7 & 8 \\
Nigeria & 37.2 & 44.9 & 2.2 & 35.6 & 4 \\
Norway & 8.1 & 8.5 & 2.0 & 14.3 & 10 \\
Saudi Arabia & 264.2 & 67.6 & 7.1 & 49.7 & -10 \\
Venezuela & 119.7 & 124.7 & 1.9 & 23.3 & 5 \\
\hline
\end{tabular}

Source: GDP data is from the IMF International Financial Statistics, oil export data is from OPEC Annual Statistical Bulletin, and oil reserve and production data is from the British Petroleum Statistical Review of World Energy. Polity, which is often used as a measure of institutional quality of a country, is an index between -10 and 10 from the Polity IV Project.

member. ${ }^{5}$ In terms of our theory what matters is the magnitude of oil reserves and the long-term sustainability of oil incomes. As can be seen from Table 1, at the current levels of production, oil reserves of Mexico and Norway are expected to last only for a further 9-10 years. Similarly, the reserve-production ratio for Indonesia is 11.2 years, with crude oil export revenue to GDP ratio of only around $2 \%$. In contrast, oil reserve-production ratios of the six major OPEC oil exporters range from a low of 45 years in the case of Nigeria to a high of 125 years for Venezuela.

While the countries under consideration have very different political systems and institutional economic arrangements, our theory suggests that these differences can only affect the estimates of the parameters rather than the nature of the long-run relationship that holds between outputs (domestic and foreign) and oil export revenues. For the applicability of our analysis, what matters most is the extent to which oil revenues are likely to be sustainable over the medium to long term, and in this regard it is the oil reserve-production ratio that could be important as to whether oil income enters the long-run output equation as a major determinant. Having a range of countries with different levels of reserve-production ratios allows us to shed further light on the relevance of the long-run theory developed in this paper.

\footnotetext{
${ }^{5}$ We would also have liked to include Russia in our study, as it is the second largest oil exporter in the world (Saudi Arabia being the first). However, due to the lack of sufficiently long time series data this was not possible.
} 


\subsection{The VARX* Error Correcting Model}

We need to set up an econometric framework within which the long-run theory can be tested. To this end we first re-write the output equation as

$$
y_{t}-\psi_{1} y_{t}^{*}=\psi_{2}\left(e_{t}-p_{t}\right)+\psi_{3} x o_{t}+c_{y}+\gamma_{y} t+\xi_{y, t}
$$

where $c_{y}$ is an unrestricted fixed constant, $\xi_{y, t}$ is a mean zero stationary process, and

$$
y_{t}=\ln \left(G D P_{t} / C P I_{t}\right), e_{t}=\ln \left(E_{t}\right), p_{t}=\ln \left(C P I_{t}\right),
$$

where $G D P_{t}$ is the nominal Gross Domestic Product, $C P I_{t}$ is the consumer price index, and $E_{t}$ is the number of domestic currency per one US dollar. The two exogenous variables in the model are foreign output, $y_{t}^{*}$, and oil income in US dollars defined as $x o_{t}=\ln \left(P_{t}^{o} X_{t}^{o}\right)$, where $P_{t}^{o}$ is the nominal price of oil per barrel in US dollars, and $X_{t}^{o}$ is the domestic oil export in thousands of barrels per day. The data for $y_{t}, e_{t}$, and $p_{t}$ are obtained from Cashin et al. (2012), while the data on oil exports, $x o_{t}$, is obtained from the OPEC Annual Statistical Bulletin. Details of the data sources is provided in a supplement which is available from the authors on request.

For the eight countries under consideration, foreign outputs were computed as trade weighted averages of $\log$ real output indices $\left(y_{j t}\right)$ of country $i$ 's trading partners. ${ }^{6}$ Specifically,

$$
y_{i t}^{*}=\sum_{j=1}^{51} w_{i j} y_{j t}, i=1,2, \ldots, 8,
$$

where $w_{i j}$ is the trade share of country $j$ for country $i$, computed as a three-year average to reduce the impact of individual yearly movements on the trade weights. ${ }^{7}$ The trade weights were computed as

$$
w_{i j}=\frac{T_{i j, 2006}+T_{i j, 2007}+T_{i j, 2008}}{T_{i .2006}+T_{i .2007}+T_{i .2008}},
$$

where $T_{i j t}$ is the bilateral trade of country $i$ with country $j$ during a given year $t$ and is calculated as the average of exports and imports of country $i$ with $j$, and $T_{i t}=\sum_{j=1}^{N} T_{i j t}$ (the total trade of country $i$ ) for $t=2006,2007,2008$, in the case of all countries except for Iran. ${ }^{8}$ As explained below, we had to use a shorter sample period for Iran, and accordingly the trade weights were based on the average of trades over the three years 2001-2003.

The long run relation given by equation (26) can be written (for a particular oil exporter) more compactly as deviation from equilibrium (the country subscript $i$ is suppressed for notational convenience):

$$
\xi_{y, t}=\boldsymbol{\beta}^{\prime} \mathbf{z}_{t}-c_{y}-\gamma_{y} t
$$

\footnotetext{
${ }^{6}$ The countries included are Algeria, Argentina, Australia, Austria, Bahrain, Belgium, Brazil, Canada, Chile, China, Ecuador, Egypt, Finland, France, Germany, India, Indonesia, Iran, Italy, Japan, Jordan, Korea, Kuwait, Lebanon, Libya, Malaysia, Mauritania, Mexico, Morocco, Netherlands, New Zealand, Nigeria, Norway, Oman, Peru, Philippines, Qatar, Saudi Arabia, Singapore, South Africa, Spain, Sweden, Switzerland, Syria, Thailand, Tunisia, Turkey, United Arab Emirates, United Kingdom, United States, and Venezuela. For more details see Cashin et al. (2012).

${ }^{7} \mathrm{~A}$ similar approach has also been followed in global VAR models estimated in the literature. See, for example, Dees et al. (2007).

${ }^{8}$ The trade weights are computed based on data from the IMF Direction of Trade Statistics and data on the foreign variables are obtained from Cashin et al. (2012).
} 
where $\mathbf{z}_{t}=\left(\mathbf{x}_{t}^{\prime}, \mathbf{x}_{t}^{* \prime}\right)^{\prime}$, with $\mathbf{x}_{t}=\left(y_{t}, e_{t}-p_{t}\right)^{\prime}, \mathbf{x}_{t}^{*}=\left(y_{t}^{*}, x o_{t}\right)^{\prime}$, and $\boldsymbol{\beta}^{\prime}=\left(\begin{array}{llll}-1 & \psi_{2} & \psi_{1} & \psi_{3}\end{array}\right)$.

The long run theory for oil exporting countries, as derived in Section 2.1, requires two further restrictions on the output equation (26), namely $\psi_{2}=\psi_{3}=\alpha$ and $\psi_{1}=\theta(1-\alpha)$, where we are interested in seeing whether in fact the coefficients of the real exchange rate and total revenues from oil exports are the same and equal to the share of capital in output $(\alpha)$ and whether technological progress in the country of interest is on par with that of the rest of the world, in other words whether $\theta=1$, and as a result the coefficient of the foreign real output is equal to $(1-\alpha)$.

The $\operatorname{VARX}^{*}\left(s, s^{*}\right)$ model that embodies $\xi_{y, t}$ is constructed from a suitably restricted version of the VAR in $\mathbf{z}_{t}$. In the present application $\mathbf{z}_{t}=\left(\mathbf{x}_{t}^{\prime}, \mathbf{x}_{t}^{* \prime}\right)^{\prime}$ is partitioned into the $2 \times 1$ vector of endogenous variables, $\mathbf{x}_{t}=\left(y_{t}, e_{t}-p_{t}\right)^{\prime}$, and the $2 \times 1$ vector of the weakly exogenous variables, $\mathbf{x}_{t}^{*}=\left(y_{t}^{*}, x o_{t}\right)^{\prime}$. In the case of all the eight countries, the hypothesis that the four variables in $\mathbf{z}_{t}$ are $I(1)$ cannot be rejected. Moreover, it is easily established that the two exogenous variables, $y_{t}^{*}$ and $x o_{t}$, are not cointegrated, again for all eight countries under consideration. ${ }^{9}$ Under these conditions, following Pesaran et al. (2000), the VAR in $\mathbf{z}_{t}$ can be decomposed into the conditional model for the endogenous variables:

$$
\Delta \mathbf{x}_{t}=-\boldsymbol{\Pi}_{x} \mathbf{z}_{t-1}+\sum_{i=1}^{s-1} \boldsymbol{\Psi}_{i} \Delta \mathbf{x}_{t-i}+\boldsymbol{\Lambda}_{0} \Delta \mathbf{x}_{t}^{*}+\sum_{i=1}^{s^{*}-1} \boldsymbol{\Lambda}_{i} \Delta \mathbf{x}_{t-i}^{*}+\mathbf{a}_{0}+\mathbf{a}_{1} t+\boldsymbol{v}_{t}
$$

and the marginal model for the exogenous variables:

$$
\Delta \mathbf{x}_{t}^{*}=\sum_{i=1}^{s-1} \Gamma_{i}^{*} \Delta \mathbf{z}_{t-i}+\mathbf{b}_{0}+\mathbf{u}_{x^{*} t}
$$

If the model includes an unrestricted linear trend, in general there will be quadratic trends in the level of the variables when the model contains unit roots. To avoid this, the trend coefficients are restricted such that $\mathbf{a}_{1}=\boldsymbol{\Pi}_{x} \boldsymbol{\delta}$, where $\boldsymbol{\delta}$ is an $4 \times 1$ vector of free coefficients, see Pesaran et al. (2000) and Section 6.3 in Garratt et al. (2006). The nature of the restrictions on $\mathbf{a}_{1}$ depends on the rank of $\boldsymbol{\Pi}_{x}$. In the case where $\boldsymbol{\Pi}_{x}$ is full rank, $\mathbf{a}_{1}$ is unrestricted, whilst it is restricted to be equal to $\mathbf{0}$ when the rank of $\boldsymbol{\Pi}_{x}$ is zero. Under the restricted trend coefficients the conditional model can be written as

$$
\Delta \mathbf{x}_{t}=-\boldsymbol{\Pi}_{x}\left[\mathbf{z}_{t-1}-\boldsymbol{\delta}(t-1)\right]+\sum_{i=1}^{s-1} \boldsymbol{\Psi}_{i} \Delta \mathbf{x}_{t-i}+\boldsymbol{\Lambda}_{0} \Delta \mathbf{x}_{t}^{*}+\sum_{i=1}^{s^{*}-1} \boldsymbol{\Lambda}_{i} \Delta \mathbf{x}_{t-i}^{*}+\tilde{\mathbf{a}}_{0}+\boldsymbol{v}_{t}
$$

where $\tilde{\mathbf{a}}_{0}=\mathbf{a}_{0}+\boldsymbol{\Pi}_{x} \boldsymbol{\delta}$. In the literature this specification is referred to as the vector error correcting model with weakly exogenous $I(1)$ variables, or $\operatorname{VECX}^{*}\left(s, s^{*}\right)$ for short. Note that $\tilde{\mathbf{a}}_{0}$ remains unrestricted since $\mathbf{a}_{0}$ is not restricted. For consistent and efficient estimation (and inference) we only require the conditional model as specified in (30).

The long-run theory imposes a number of restrictions on $\boldsymbol{\Pi}_{x}$ and $\boldsymbol{\delta}$. First, for the conditional model to embody the equilibrium error defined by, (29), we must have $\boldsymbol{\Pi}_{x}=\boldsymbol{\alpha}_{x} \boldsymbol{\beta}^{\prime}$, which in turn implies that $\operatorname{rank}\left(\boldsymbol{\Pi}_{x}\right)=1$. Furthermore, the restrictions on the trend coefficients are given by $\Pi_{x} \boldsymbol{\delta}=\boldsymbol{\alpha}_{\mathbf{x}} \boldsymbol{\beta}^{\prime} \boldsymbol{\delta}=\boldsymbol{\gamma}$. Since under cointegration $\boldsymbol{\alpha}_{x} \neq \mathbf{0}$, it then follows that

\footnotetext{
${ }^{9}$ To save space these test results are not reported here but are available on request.
} 
a trend will be absent from the long run relations if $\boldsymbol{\beta}^{\prime} \boldsymbol{\delta}=\mathbf{0}$. These restrictions are known as co-trending restrictions, meaning that the linear trends in the various variables of the long run relations get cancelled out. This hypothesis is important in the analysis of output convergence between domestic and the foreign variables, since without such a co-trending restriction the two output series will diverge even if they are shown to be cointegrated.

\subsection{Tests and Estimation Results}

With the exception of Iran all country specific $\operatorname{VARX}^{*}\left(s_{i}, s_{i}^{*}\right)$ models are estimated using quarterly observations over the period 1979Q1-2009Q4. We had to estimate the model for Iran over the shorter sample period of 1979Q1-2006Q4, since no official national account data have been released by Iran from 2007 onwards. The lag orders, $s_{i}$ and $s_{i}^{*}$, were selected using Akaike Information Criterion (AIC) and Schwarz Bayesian Criterion (SBC), setting the maximum lag orders to $s_{\max }=4$ and $s_{\max }^{*}=2$. It is interesting that the selected lag orders ended up to be $\hat{s}_{i}=2$ and $\hat{s}_{i}^{*}=1$, the same across all eight countries. Using Johansen's maximum eigenvalue and trace statistics we then tested the null of no cointegration between $\mathbf{x}_{t}=\left(y_{t}, e_{t}-p_{t}\right)^{\prime}$ and $\mathbf{x}_{t}^{*}=\left(y_{t}^{*}, x o_{t}\right)^{\prime}$.

The cointegration test results are summarized in Table 2, and clearly reject the null of no cointegration at 5\% level in the case of Iran, Kuwait, Saudi Arabia and Venezuela, when using the trace test. The null is also rejected at $10 \%$ level in the case of Libya. For the two remaining economies, Norway and Mexico, the null of no cointegration cannot be rejected even at $10 \%$ level. Similar test results are obtained when using the maximum eigenvalue test, although the trace test is often preferred based on its more satisfactory small sample properties.

Overall, the test results are supportive of the existence of a long-run relationship between domestic output and real oil income for most of the major oil exporters. The exceptions, Noway and Mexico, could be explained either by lack of power of the cointegration test, or the fact that oil income has not been sufficiently dominant in these economies. The lack of power argument seems less convincing in the present applications since the time series sample used is relatively long $(T=121)$, and we obtain rejection in the case of Kuwait, Libya, Nigeria, Saudi Arabia and Venezuela using the same sample size, and for Iran even when a slightly smaller sample size is used. It seems more plausible to conclude that oil income has not been sufficiently important for Mexico and Norway over the sample period under consideration. This view is further supported by the fact that the oil reserve-production ratios of these economies (at 9 and 10 years) are much lower than those of the other six major oil exporters (ranging from 45 to 125 years) included in our study. See the discussion in Section 3 and Table 1.

In the second stage of our empirical evaluation we focussed on the six countries for which the existence of the long-run relation, inclusive of the oil income variable, could not be rejected. We estimated the output equation, (26), subject to the co-trending restriction, $\gamma_{y}=0$. The log-likelihood ratio (LR) statistic for testing the co-trending restriction is asymptotically distributed as a chi-squared variate with one degree of freedom. But we are working with a relatively large dimensional VARX* model using a moderate number of time series observations. In such situations it is known that the LR tests could over-reject in small samples (see, for example, Gredenhoff and Jacobson (2001) as well as Gonzalo 
Table 2: Cointegration Rank Test Statistics for the VARX*(2,1) Models with Endogenous Variables (y, ep) and the Weakly Exogenous Variables ( $y^{*}$, xo)

\begin{tabular}{|c|c|c|c|}
\hline \multicolumn{4}{|c|}{ Iran } \\
\hline \multirow[b]{2}{*}{$H_{0} \quad H_{1}$} & \multirow[b]{2}{*}{ Statistic } & \multicolumn{2}{|c|}{ Critical Values } \\
\hline & & $5 \%$ & $10 \%$ \\
\hline \multicolumn{4}{|c|}{ (a) Maximal eigenvalue statistic } \\
\hline$r=0 r=1$ & 31.78 & 26.10 & 24.04 \\
\hline$r \leq 1 r=2$ & 8.23 & 18.41 & 16.38 \\
\hline \multicolumn{4}{|c|}{ (b) Trace statistic } \\
\hline$r=0 r=1$ & 40.00 & 37.50 & 34.56 \\
\hline$r \leq 1 r=2$ & 8.23 & 18.41 & 16.38 \\
\hline
\end{tabular}

\begin{tabular}{|c|c|c|c|c|}
\hline \multicolumn{5}{|c|}{ Kuwait } \\
\hline & & & Critic & Values \\
\hline$H_{0}$ & $H_{1}$ & Statistic & $5 \%$ & $10 \%$ \\
\hline \multicolumn{5}{|c|}{ (a) Maximal eigenvalue statistic } \\
\hline$r=0$ & $r=1$ & 32.14 & 27.17 & 24.42 \\
\hline$r \leq 1$ & $r=2$ & 17.83 & 18.22 & 16.23 \\
\hline \multicolumn{5}{|c|}{ (b) Trace statistic } \\
\hline$r=0$ & $r=1$ & 49.97 & 37.78 & 33.83 \\
\hline$r \leq 1$ & $r=2$ & 17.83 & 18.22 & 16.23 \\
\hline
\end{tabular}

\section{Libya}

\begin{tabular}{lccc}
\hline \multicolumn{5}{c}{ Critical Values } \\
$H_{0} H_{1}$ & Statistic & $5 \%$ & $10 \%$ \\
\hline (a) Maximal eigenvalue statistic \\
$r=0 r=1$ & 27.55 & 27.17 & 24.42 \\
$r \leq 1 r=2$ & 6.49 & 18.22 & 16.23 \\
$(\mathbf{b})$ Trace & statistic & \\
$r=0 r=1$ & 34.04 & 37.78 & 33.83 \\
$r \leq 1 r=2$ & 6.49 & 18.22 & 16.23 \\
\hline \multicolumn{5}{c}{ Nigeria } \\
\hline \multicolumn{5}{c}{ Critical Values } \\
$H_{0} H_{1}$ & Statistic & $5 \%$ & $10 \%$ \\
\hline (a) Maximal eigenvalue statistic \\
$r=0 r=1$ & 27.63 & 27.17 & 24.42 \\
$r \leq 1 r=2$ & 5.76 & 18.22 & 16.23 \\
$(\mathbf{b})$ Trace statistic & \\
$r=0 r=1$ & 33.40 & 37.78 & 33.83 \\
$r \leq 1 r=2$ & 5.76 & 18.22 & 16.23 \\
\hline
\end{tabular}

\section{Saudi Arabia}

\begin{tabular}{|c|c|c|c|}
\hline \multirow[b]{2}{*}{$H_{H}$} & \multirow[b]{2}{*}{ Statistic } & \multicolumn{2}{|c|}{ Critical Values } \\
\hline & & $5 \%$ & $10 \%$ \\
\hline \multicolumn{4}{|c|}{ (a) Maximal eigenvalue statistic } \\
\hline$r=0 r=1$ & 29.22 & 27.17 & 24.42 \\
\hline$r \leq 1 r=2$ & 19.17 & 18.22 & 16.23 \\
\hline \multicolumn{4}{|c|}{ (b) Trace statistic } \\
\hline$r=0 r=1$ & 48.39 & 37.78 & 33.83 \\
\hline$r \leq 1 r=2$ & 19.17 & 18.22 & 16.23 \\
\hline
\end{tabular}

\section{Mexico}

\begin{tabular}{lcccc}
\hline & \multicolumn{3}{c}{ Critical Values } \\
$H_{0}$ & $H_{1}$ & Statistic & $5 \%$ & $10 \%$ \\
\hline \multicolumn{2}{l}{ (a) } & Maximal & eigenvalue & statistic \\
$r=0$ & $r=1$ & 18.49 & 27.17 & 24.42 \\
$r \leq 1$ & $r=2$ & 11.17 & 18.22 & 16.23 \\
(b) Trace statistic & & \\
$r=0$ & $r=1$ & 29.66 & 37.78 & 33.83 \\
$r \leq 1$ & $r=2$ & 11.17 & 18.22 & 16.23 \\
\hline
\end{tabular}

\begin{tabular}{|c|c|c|c|c|}
\hline \multicolumn{5}{|c|}{ Norway } \\
\hline \multirow[b]{2}{*}{$H_{0}$} & \multirow[b]{2}{*}{$H_{1}$} & \multirow[b]{2}{*}{ Statistic } & \multicolumn{2}{|c|}{ Critical Values } \\
\hline & & & $5 \%$ & $10 \%$ \\
\hline \multicolumn{5}{|c|}{ (a) Maximal eigenvalue statistic } \\
\hline$r=0$ & $r=1$ & 10.08 & 27.17 & 24.42 \\
\hline$r \leq 1$ & $r=2$ & 7.68 & 18.22 & 16.23 \\
\hline \multicolumn{5}{|c|}{ (b) Trace statistic } \\
\hline$r=0$ & $r=1$ & 17.77 & 37.78 & 33.83 \\
\hline$r \leq 1$ & $r=2$ & 7.68 & 18.22 & 16.23 \\
\hline
\end{tabular}

\begin{tabular}{|c|c|c|c|c|}
\hline \multicolumn{5}{|c|}{ Venezuela } \\
\hline & & & Critic & Values \\
\hline$H_{0}$ & $H_{1}$ & Statistic & $5 \%$ & $10 \%$ \\
\hline \multicolumn{5}{|c|}{ (a) Maximal eigenvalue statistic } \\
\hline$r=0$ & $r=1$ & 25.95 & 27.17 & 24.42 \\
\hline$r \leq 1$ & $r=2$ & 16.54 & 18.22 & 16.23 \\
\hline \multicolumn{5}{|c|}{ (b) Trace statistic } \\
\hline$r=0$ & $r=1$ & 42.49 & 37.78 & 33.83 \\
\hline$r \leq 1$ & $r=2$ & 16.54 & 18.22 & 16.23 \\
\hline
\end{tabular}

Notes: All the underlying VARX* models are of order $(2,1)$ and contain unrestricted intercept and restricted trend coefficients. $y_{t}^{*}$ and $x o_{t}$ are treated as weakly exogenous, non-cointegrated $I(1)$ variables. The test statistics refer to Johansen's log-likelihood-based maximum eigenvalue and trace statistics and are computed using 110 observations from 1979Q3 to 2006Q4 for Iran and 121 observations from 1979Q4 to 2009Q4 for all other countries. The 5 percent and 10 percent simulated critical values are computed by stochastic simulations and 1000 replications. 
(1994), Haug (1996) and Abadir et al. (1999)). To deal with the small sample problem we computed bootstrapped critical values based on 1,000 replications of the LR statistic. Using the observed initial values of each variable, the estimated model, and a set of random innovations, an artificial data set is generated for each of the 1,000 replications under the assumption that the estimated version of the model is the true data-generating process. For each of the replicated data sets, we first estimate our $\mathrm{VECX}^{*}$ model subject to the exact identifying restriction (which sets the coefficient of $y_{t}$ equal to -1 ), and then subject to the co-trending restriction. Finally, the empirical distribution of the LR test statistic is derived using the 1,000 replications.

The LR statistics for the co-trending restriction $\left(\gamma_{y}=0\right)$ are summarized on the left panel of Table 3, together with the associated 1\%, $5 \%$, and $10 \%$ bootstrapped critical values. The test results clearly show that except for Iran the co-trending restriction cannot be rejected at the $1 \%$ level for the other five countries. If we adopt the $5 \%$ level, the co-trending restriction is rejected in the case of Nigeria, but overall the test results support the restrictions, and suggest that trend output growth in these economies is broadly in line with trends in output growths in the rest of the world. The clear rejection of the co-trending restriction in the case of Iran could reflect Iran's relative isolation from the global economy over the past 30 years, since the 1979 Revolution. In addition to the initial economic disruptions due to the Revolution, other factors such as the eight-year war with Iraq, and the prolonged period of economic sanctions by the US and some of the European economies against Iran could have further contributed to this outcome.

Subject to the co-trending restriction, we then tested the further theory restriction given by $\psi_{2}=\psi_{3}=\alpha$, see (25). The test results are summarized on the right panel of Table 3. The joint hypothesis of $\gamma_{y}=0$ and $\psi_{2}=\psi_{3}$ cannot be rejected at the $1 \%$ level for all countries considered with the exception of Iran. Under these restrictions the estimates of $\psi_{1}$ and $\psi_{2}(=\alpha)$ together with their asymptotic standard errors are provided in Table 3, as well as an implied estimate of $\theta$, computed as $\widehat{\theta}=\widehat{\psi}_{1} /\left(1-\hat{\psi}_{2}\right) \cdot{ }^{10}$ The parameter estimates, $\hat{\psi}_{1}$ and $\hat{\psi}_{2}(=\hat{\alpha})$, all have the correct signs and are highly statistically significant, with the exception of the estimate of $\alpha$ for Nigeria, which is statistically significant only at the $10 \%$ level, and is not that well estimated. The estimates of $\alpha$ for the remaining five countries (including the estimate obtained for Iran where the theory restrictions are rejected), lie in the relatively narrow range of 0.11 (for Iran) to 0.18 (for Venezuela). These estimates are in line with the estimate of between 0.115 and 0.172 reported for a panel of oil exporting countries in Cavalcanti et al. (2011a) and between 0.13 and 0.20 for a panel of 51 countries in Pedroni (2007). For all countries, but Libya, the implied estimates of $\theta$ is larger than 0.70, and suggest a reasonable but partial diffusion and adaptation of technological advancement for the major oil exporters. In this regard Libya seems to have been left out. The result for Iran should also be treated with caution considering that the co-trending restrictions has already been rejected in her case.

We also considered the effects of setting $\theta=1$ on the estimates of $\alpha$. The results are summarized in Table 4. Imposing such a restriction seems to be innocuous in the case of Iran, Kuwait and Nigeria, and results in relatively small increases in the LR statistic and

\footnotetext{
${ }^{10}$ All estimations and test results are obtained using Microfit 5.0. For further technical details see Pesaran and Pesaran (2009), Section 22.10.
} 


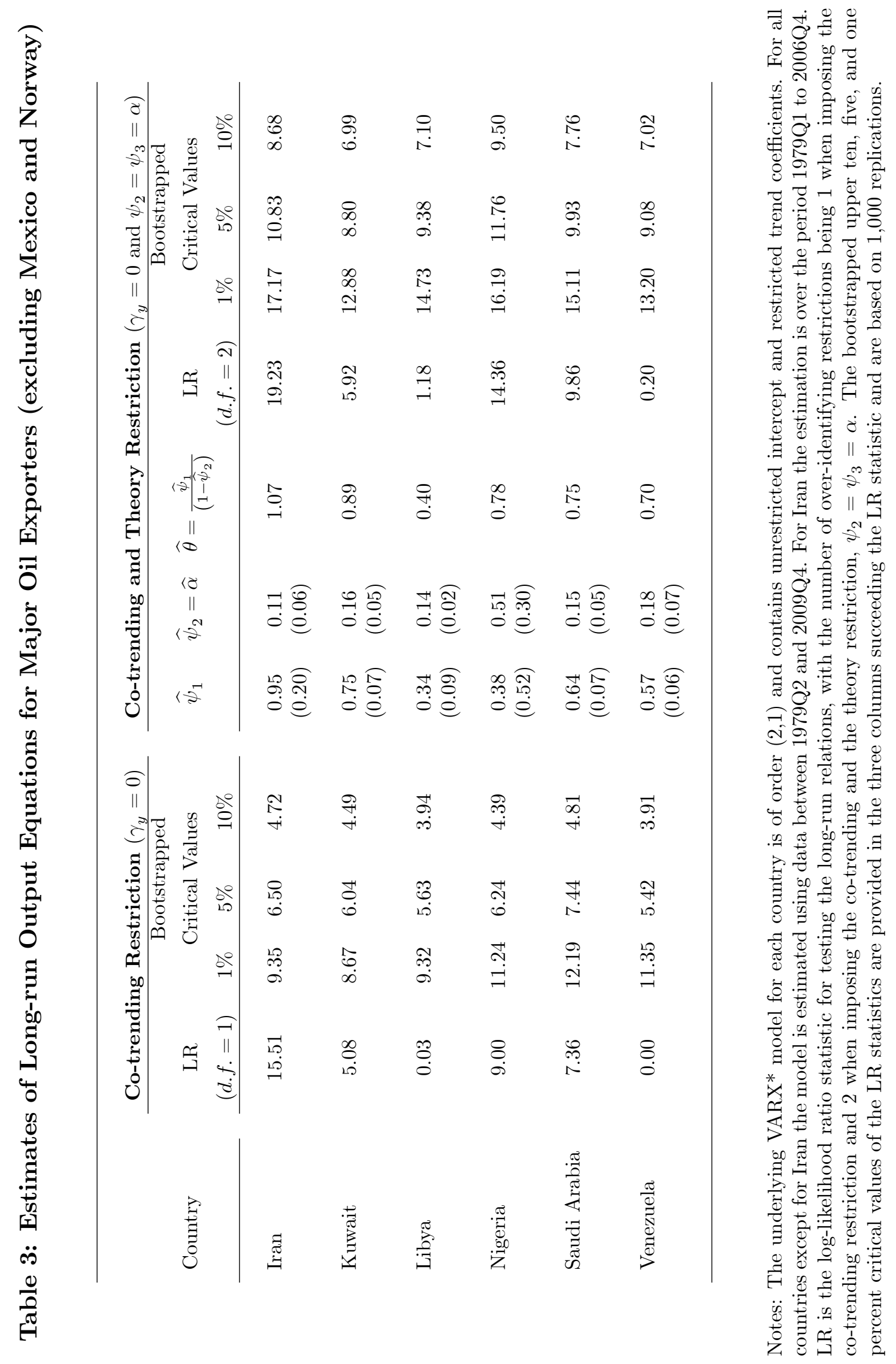


hardly changes the estimate of $\alpha$. However, the imposition of $\theta=1$ significantly raises the LR statistics for the remaining countries. Overall we favour the cross-country estimates provided in Table 3 where the restriction $\theta=1$ is not imposed.

Table 4: Estimates of the Share of Capital in Output for Major Oil Exporters Assuming that Domestic Technological Progress is on par with that of the Rest of the World

\begin{tabular}{lccccc}
\hline \multirow{2}{*}{ Country } & $\widehat{\psi}_{2}=\widehat{\alpha}$ & LR & \multicolumn{4}{c}{ Bootstrapped } \\
& & $(d . f .=3)$ & $1 \%$ & $5 \%$ & $10 \%$ \\
\hline \multirow{2}{*}{ Iran } & 0.13 & 19.40 & 20.62 & 13.07 & 10.37 \\
& $(0.05)$ & & & & \\
Kuwait & 0.14 & 7.80 & 15.57 & 10.96 & 9.25 \\
& $(0.06)$ & & & & \\
Libya & 0.07 & 11.27 & 19.31 & 13.50 & 10.99 \\
& $(0.05)$ & & & & \\
Nigeria & 0.49 & 14.48 & 19.06 & 14.03 & 11.82 \\
& $(0.28)$ & & & & \\
Saudi Arabia & 0.25 & 11.23 & 19.31 & 13.43 & 10.89 \\
& $(0.08)$ & & & & \\
Venezuela & 0.35 & 3.21 & 17.83 & 12.01 & 10.07 \\
& $(0.09)$ & & & & \\
\hline
\end{tabular}

Notes: The underlying VARX* model for each country is of order $(2,1)$ and contains unrestricted intercept and restricted trend coefficients. For all countries except for Iran the model is estimated using data between 1979Q2 and 2009Q4. For Iran the estimation is over the period 1979Q1 to 2006Q4. LR is the log-likelihood ratio statistic for testing the long-run relations, testing jointly three over-identifying restrictions, namely the co-trending restriction $\left(\gamma_{y}=0\right)$, the theory restriction $\left(\psi_{2}=\psi_{3}=\alpha\right)$, and $\theta=1$. The bootstrapped upper ten, five, and one percent critical values of the LR statistics are computed with 1,000 replications. 


\subsection{A Former OPEC Member: The Case of Indonesia}

The long-run output relation for major oil exporting economies developed in this paper has so far only been tested on countries, where the oil income to output ratio is expected to remain high over a prolonged period. However, there are many cases in which a country has exported large quantities of oil, but as its oil production peaks (and domestic consumption increases) it finds its oil income falling drastically. An example of such a country is Indonesia which joined OPEC in 1962 but suspended its membership from January 2009. While Indonesian oil production peaked in mid 1990's, the share of oil exports in GDP has been declining steadily over the past three decades, implying that $g^{o}<g+n$. Therefore, we need to distinguish between the two cases where the growth of oil income, $g^{0}$, is less than the natural growth rate (the sum of the population growth, $n$, and the growth of technical progress, $g$ ) and when $g^{0} \geq g+n$. Under the former, the effects of oil income on the economy's steady growth rate will vanish eventually, as is indeed the case for Indonesia.

We test our theory by using quarterly data on Indonesia, but before estimation we need to determine the lag order of the VARX* model as well as the number of cointegrating relations As for the other countries both the SBC and AIC select $\hat{s}=2$ and $\hat{s}^{*}=1$ for Indonesia. Moreover, the maximal eigenvalue and the trace statistics suggest the presence of one cointegrating relations at the 5 percent and 10 percent levels respectively (Table 5), which is the same as that suggested by economic theory, thus we set $r=1$.

Table 5: Cointegration Rank Test Statistics for the $\operatorname{VARX} *(2,1)$ Model with Endogenous Variables (y, ep) and the Weakly Exogenous Variables $\left(\mathrm{y}^{*}, \mathrm{xo}\right)$

\begin{tabular}{|c|c|c|c|c|}
\hline$H_{0}$ & $H_{1}$ & Test statistic & 95\% Critical Values & 90\% Critical Values \\
\hline \multicolumn{5}{|c|}{ (a) Maximal eigenvalue statistic } \\
\hline$r=0$ & $r=1$ & 30.66 & 27.17 & 24.42 \\
\hline$r \leq 1$ & $r=2$ & 6.54 & 18.22 & 16.23 \\
\hline \multicolumn{5}{|c|}{ (b) Trace statistic } \\
\hline$r=0$ & $r=1$ & 37.20 & 37.78 & 33.83 \\
\hline$r \leq 1$ & $r=2$ & 6.54 & 18.22 & 16.23 \\
\hline
\end{tabular}

Notes: The underlying VARX* model is of order $(2,1)$ and contains unrestricted intercept and restricted trend coefficients. $y_{t}^{*}$ and $x o_{t}$ are treated as weakly exogenous, non-cointegrated $I(1)$ variables. The test statistics refer to Johansen's log-likelihood-based maximum eigenvalue and trace statistics and are computed using 121 observations from 1979Q4 to 2009Q4.

Imposing $\psi_{2}=\psi_{3}$ together with $\theta=1$, we obtain the estimates (standard errors in brackets), $\widehat{\psi}_{2}=0.0020$ (0.0039) and $\widehat{\psi}_{1}=0.998$ (0.039), which confirms that $\psi_{2}=\psi_{3} \approx 0$. Imposing $\psi_{2}=\psi_{3}=0$, the LR statistic for testing all the 5 restrictions jointly is 24.58 which is to be compared with the bootstrapped critical values of 19.48 and 25.41, implying that the restrictions are rejected at the 5 percent level but not at the 1 percent level. Therefore, in line with the theoretical discussions in Section 2.1 we conclude that oil income does not enter the long-run output equation for Indonesia. Similar findings are also to be expected for other oil exporters with the growth of oil income, $g^{o}$, below the natural growth rate, $g+n$, as was also found in the case of Mexico and Norway. 


\section{Impulse Response Effects of Shocks to Oil Exports and Foreign Output}

The country specific VARX* models estimated in this paper can also be used to examine the short term effects of shocks to oil exports and foreign output. ${ }^{11}$ This is complementary to the analysis of the effects of oil price shocks on advanced economies that have been investigated extensively in the literature. Initially, we consider the effects of system-wide shocks on the long-run output equations using the persistence profiles, developed by Lee and Pesaran (1993) and Pesaran and Shin (1996). On impact the persistence profiles (PP) are normalized to take the value of unity, but the rate at which they tend to zero provide information on the speed with which equilibrium correction takes place in response to shocks. The PP could initially over-shoot, thus exceeding unity, but must eventually tend to zero if the long-run relationship under consideration is cointegrating. To investigate the effects of variable specific shocks on the oil exporters we make use of the Generalized Impulse Response Functions (GIRFs), developed in Koop et al. (1996) and Pesaran and Shin (1998). Unlike the orthogonalized impulse responses popularized in macroeconomics by Sims (1980), the GIRFs are invariant to the ordering of the variables in the VARX* model.

We shall focus on the six major oil exporters that pass the cointegration test, and do not include Noway and Mexico in our analysis. For these two economies the PP and GIRFs do not stabilize even after 40 quarters, supporting the outcome of the cointegration tests reported in Table 2.

\subsection{Persistence Profiles}

The Persistence Profiles for the six major oil exporters, together with their $95 \%$ bootstrapped error bands are provided in Figure 2. The profiles overshoot before quickly tending to zero. This is the case for all of the six oil exporters. The speed of convergence is very fast and equilibrium is established after 2-3 years in most cases. Amongst the six countries, Venezuela shows the fastest rate of convergence (around 2 years), and Saudi Arabia the slowest rate of convergence (3-4 years). The 95\% error bands are quite tight and widen somewhat initially before narrowing down to zero. Overall, the profiles are well estimated with the possible exception of the PP for Nigeria. What is most striking is the much faster speed of convergence obtained for the major oil exporters as compared, for example, with the speed of convergence of output equations reported in Garratt et al. (2006) and AssenmacherWesche and Pesaran (2009) for the UK and Switzerland respectively. This could be due to the absence of fully developed capital and money markets in the economies of the major oil exporters under consideration, which in turn allow little possibility for shock absorptions. The recently established Sovereign Wealth Funds by oil exporters could, in principle, if used appropriately act as shock absorbers which might lead to a more sluggish response of these

\footnotetext{
${ }^{11}$ For the purpose of impulse response analysis, the conditional model (30) is augmented with the following marginal models for the exogenous variables

$$
\Delta y_{t}^{*}=\mu^{*}+\rho^{*} \Delta y_{t-1}^{*}+\varepsilon_{t}^{*}, \text { and } \Delta x o_{t}=\mu^{o}+\rho^{o} \Delta x o_{t-1}+\varepsilon_{t}^{o}
$$
}


economies to shocks in the future.

Figure 2: Persistence Profiles of the Effect of a System-wide Shock to the Cointegrating Relation (with 95 percent bootstrapped confidence bounds)
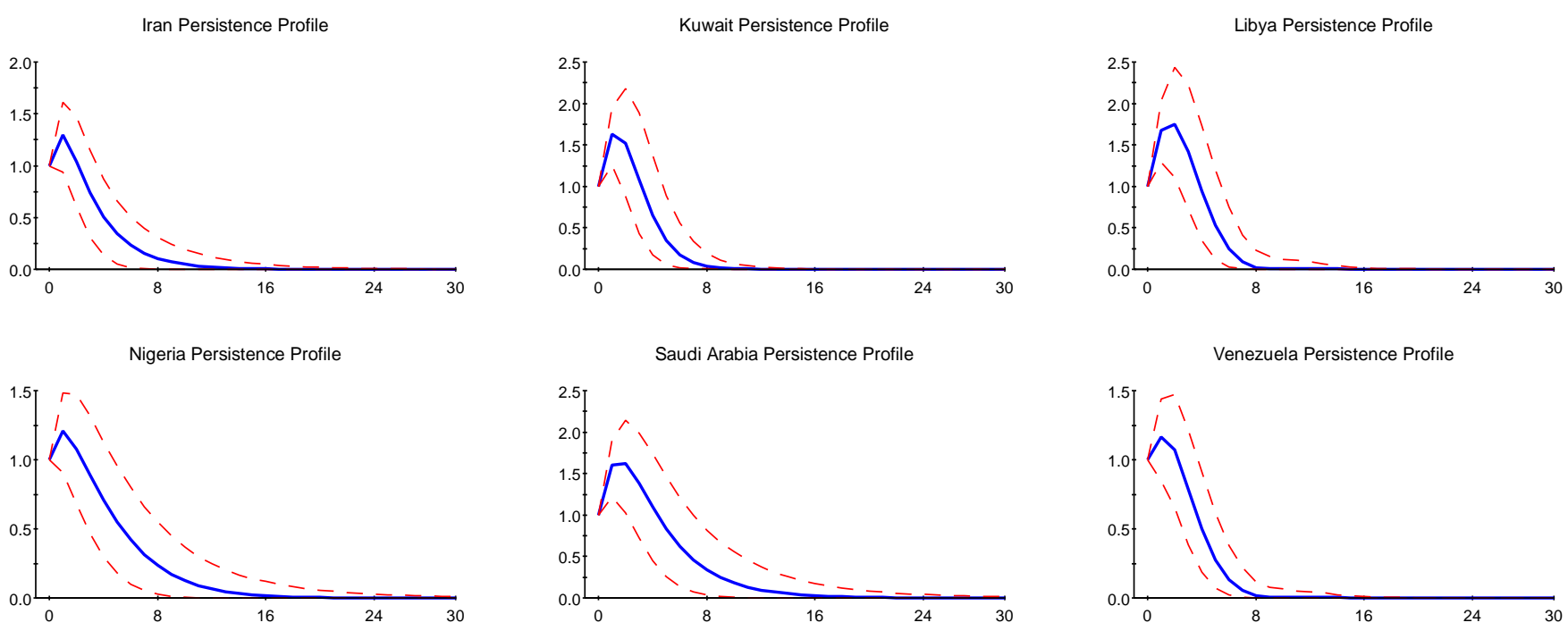

\subsection{Generalized Impulse Responses}

Generalized Impulse Response Functions (GIRFs) can be computed for shocks to any of the variables in the model, but they are more straightforward to interpret in the case of shocks to the exogenous variables, namely oil exports and foreign output.

Consider first the output effects of a unit shock (equal to one standard error) to oil export revenues. The associated GIRFs together with their 95\% error bands are given in Figure 3. These figures clearly show that a positive shock to oil exports significantly increases real output in all six major oil exporters. In line with the rapid decay of the Persistence Profiles, the full impacts of oil revenue changes show up in these economies quite fast, and peak within 2-3 years in all cases. The equilibrium levels of these effects $(3 \%-4 \%)$ are also quite similar across the economies, with the notable exception of Kuwait where the steady state value of the effect of the oil export shock is around $9 \%$. This difference partly reflects the much higher historical volatility of oil export revenues in Kuwait (due to invasion of Kuwait by Iraq in 1990 and its aftermath). The quarterly standard deviation of oil export revenues for Kuwait is around $35.5 \%$ as compared to $16.2 \%$ for Venezuela and Libya, $16.4 \%$ for Nigeria, $17.2 \%$ for Saudi Arabia, and $28.8 \%$ for Iran.

Figure 4 gives the plots of GIRFs for the effects of a unit shock to foreign output on domestic output across the six oil exporters. In comparison to the effects of shocks to oil export revenues, the effects of foreign output shocks are muted and in some cases rather poorly determined as judged by the $95 \%$ bootstrapped error bands. As to be expected from 
Figure 3: Generalized Impulse Responses of a Positive Unit shock to Oil Export Revenues (with 95 percent bootstrapped confidence bounds)
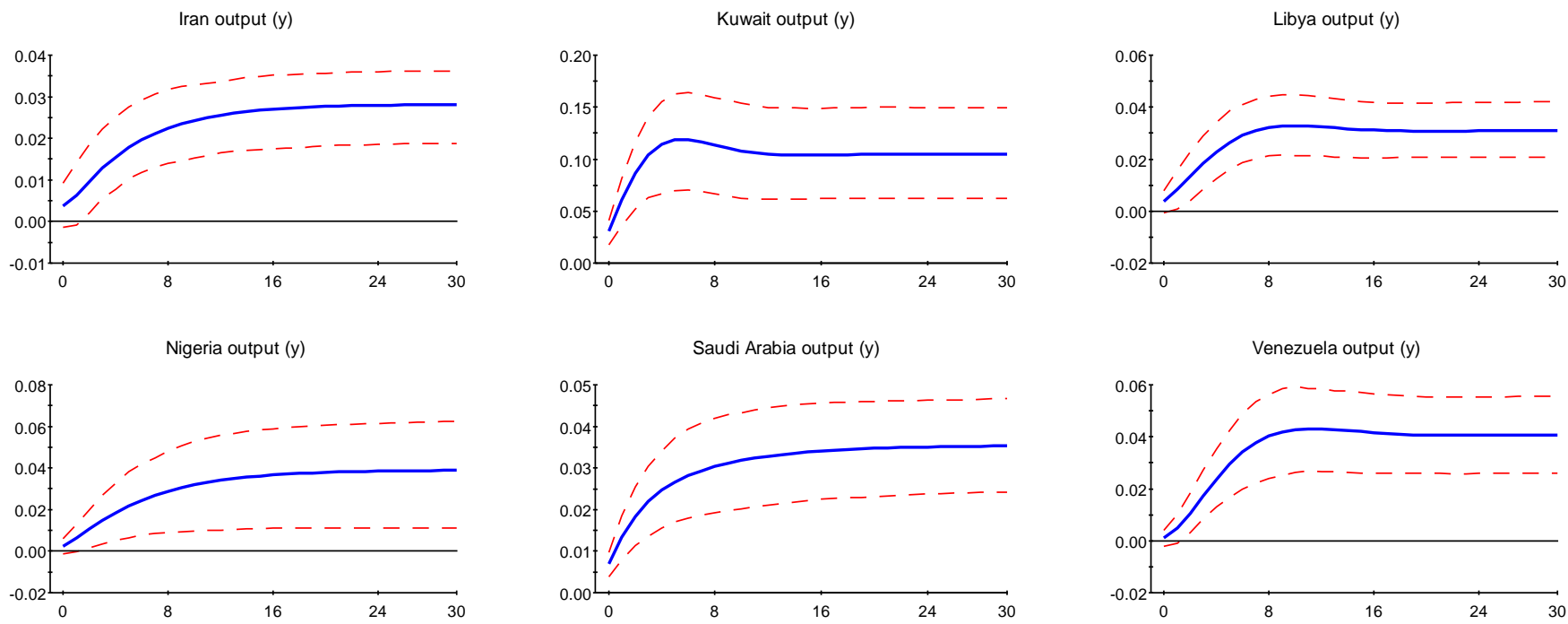

Figure 4: Generalized Impulse Responses of a Positive Unit Shock to Foreign Output (with 95 percent bootstrapped confidence bounds)

Iran output (y)

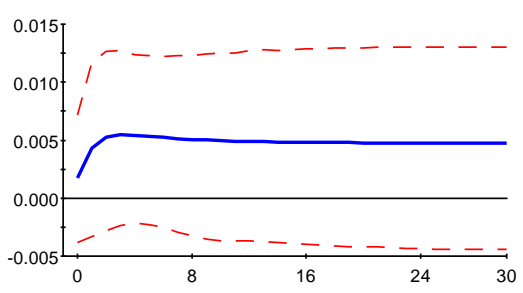

Nigeria output (y)

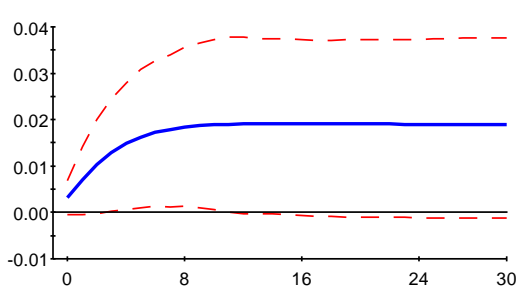

Kuwait output (y)

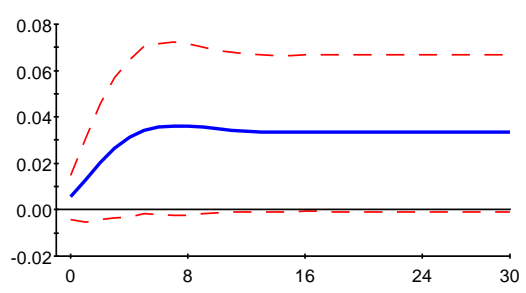

Saudi Arabia output (y)

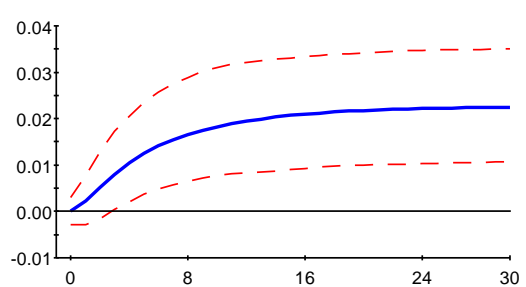

Libya output (y)

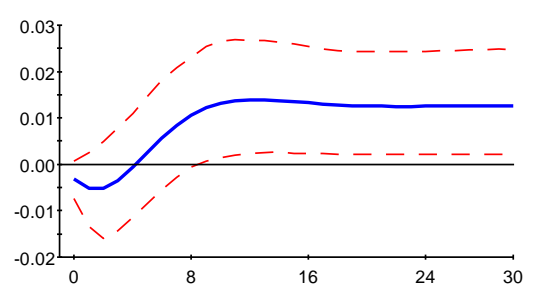

Venezuela output (y)

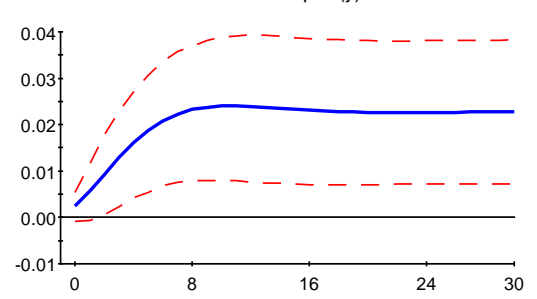


the cointegration test results the GIRFs all settle down within 2-3 years, with statistically significant permanent long-run effects, except for Iran where the effects of foreign output shocks are statistically insignificant at all horizons. This is not surprising, given the Iranian economy's relative isolation from the rest of the world, and is in line with the rejection of the co-trending restriction reported above.

\section{Concluding Remarks}

This paper makes a theoretical contribution by showing the conditions under which income from a resource can have a lasting impact on growth and per capita income. Using this theoretical insight, it provides small quarterly models for eight major oil exporting economies, six OPEC member countries (Iran, Kuwait, Libya, Nigeria, Saudi Arabia, and Venezuela) as well as two OECD countries (Mexico and Norway), where the long-run implications of oil exports for real output are tested. The results are supportive of the long-run theory, and the estimated shares of capital are generally in line with those estimates provided in the literature.

Moreover, this paper distinguishes between the oil exporters for which oil income-GDP ratios have remained relatively stable (or in some cases increased) and those for which the growth of oil income, $g^{0}$, is less than the natural growth rate, $g^{0}<g+n$. An example of the latter group is Indonesia, which recently left OPEC and has had its share of oil export revenue in income falling for several decades. Using data on Indonesia, it is shown that if $g^{0}<g+n$, then the effects of oil income on the economy's steady growth rate will eventually vanish as there is no evidence for a long-run impact of oil income on real output.

The Persistence Profiles of the effects of system-wide shocks on cointegrating relations, and the impulse response analysis of the effects of shocks to oil export revenues and foreign output, all point to a rather rapid adjustment of oil exporters to shocks. The effects of these shocks work themselves out within 2-3 years in most economies, the exception being Saudi Arabia where it takes 3-4 years for the effects of shocks to die out completely.

The research in this paper can be extended in a number of directions. It is desirable to develop a more complete model for the OPEC member countries, possibly including other important variables such as inflation, interest rates, as well as other foreign variables. The current VARX* models for the major oil exporters can be connected to the rest of the world through oil exports and foreign real output. Although these are clearly the most important channels of the transmission of shocks to oil economies, there could be others. It would be interesting to see if the country-specific models of oil exporters can be linked to the global model recently developed in Dees et al. (2007), where the differential effects of supply and demand shocks and different regional shocks on the eight oil economies could be investigated.

The theoretical results of the paper can also be extended to allow for interactions between the oil and non-oil sectors and the short-term effects of oil price volatility. Such an extension could, for example, help shed light on the importance of the National Development Fund in Iran or the sovereign wealth funds formed in other oil exporting countries as shock absorbers. 


\section{References}

Abadir, K., K. Hadri, and E. Tzavalis (1999). The Influence of VAR Dimensions on Estimator Biases. Econometrica 6\%, 163-181.

Amuzegar, J. (2008). Iran's Oil as a Blessing and a Curse. The Brown Journal of World Affairs 15, 46-61.

Assenmacher-Wesche, K. and M. H. Pesaran (2009). A VECX* Model of the Swiss Economy. Swiss National Bank Economic Studies No. 6.

Binder, M. and M. Pesaran (1999). Stochastic Growth Models and Their Econometric Implications. Journal of Economic Growth 4, 139-183.

Brunnschweiler, C. N. and E. H. Bulte (2008). The Resource Curse Revisited and Revised: A Tale of Paradoxes and Red Herrings. Journal of Environmental Economics and Management 55(3), 248-264.

Caselli, F. and T. Cunningham (2009). Leader Behaviour and the Natural Resource Curse. Oxford Economic Papers 61(4), 628-650.

Cashin, P., K. Mohaddes, and M. Raissi (2012). A Global VAR Model of MENA Business Cycles. IMF Working Paper (forthcoming).

Cavalcanti, T. V. d. V., K. Mohaddes, and M. Raissi (2011a). Growth, Development and Natural Resources: New Evidence Using a Heterogeneous Panel Analysis. The Quarterly Review of Economics and Finance 51, 305-318.

Cavalcanti, T. V. d. V., K. Mohaddes, and M. Raissi (2011b). Does Oil Abundance Harm Growth? Applied Economics Letters 18(12), 1181-1184.

Cavalcanti, T. V. d. V., K. Mohaddes, and M. Raissi (2012). Commodity Price Volatility and the Sources of Growth. IMF Working Paper WP/12/12.

Collier, P. and A. Hoeffler (2004). Greed and Grievance in Civil War. Oxford Economic Papers 56, 563-595.

Corden, W. M. and J. P. Neary (1982). Booming Sector and De-Industrialisation in a Small Open Economy. The Economic Journal 92(368), 825-848.

Dees, S., F. di Mauro, M. H. Pesaran, and L. V. Smith (2007). Exploring the International Linkages of the Euro Area: A Global VAR Analysis. Journal of Applied Econometrics 22, $1-38$.

Garratt, A., K. Lee, M. H. Pesaran, and Y. Shin (2003). A Long Run Structural Macroeconometric Model of the UK. The Economic Journal 113, 412-455.

Garratt, T., K. Lee, M. H. Pesaran, and Y. Shin (2006). Global and National Macroeconometric Modelling: A Long Run Structural Approach. Oxford University Press, Oxford. 
Gonzalo, J. (1994). Five Alternative Methods of Estimating Long-run Equilibrium Relationships. Journal of Econometrics 60(1-2), $203-233$.

Gredenhoff, M. and T. Jacobson (2001). Bootstrap Testing Linear Restrictions on Cointegrating Vectors. Journal of Business and Economic Statistics 19, 63-72.

Haug, A. (1996). Tests for Cointegration A Monte Carlo Comparison. Journal of Econometrics 71, 89-115.

Koop, G., M. H. Pesaran, and S. M. Potter (1996). Impulse Response Analysis in Nonlinear Multivariate Models. Journal of Econometrics 74, 119-147.

Krugman, P. (1987). The Narrow Moving Band, the Dutch Disease, and the Competitive Consequences of Mrs. Thatcher: Notes on Trade in the Presence of Dynamic Scale Economies. Journal of Development Economics 27(1-2), 41-55.

Lane, P. R. and A. Tornell (1996). Power, Growth, and the Voracity Effect. Journal of Economic Growth 1, 213-241.

Lee, K. and M. H. Pesaran (1993). Persistence Profiles and Business Cycle Fluctuations in a Disaggregated Model of UK Output Growth. Ricerche Economiche 47, 293-322.

Leite, C. and M. Weidmann (1999). Does Mother Nature Corrupt? Natural Resources, Corruption and Economic Growth. IMF Working Paper No. 99/85.

Mahdavi, H. (1970). The Patterns and Problems of Economic Development in Rentier States: The Case of Iran. In M. Cook (Ed.), Studies in the Economic History of the Middle East. Oxford University Press, London, UK.

Mauro, P. (1995). Corruption and Growth. The Quarterly Journal of Economics 110(3), $681-712$.

Neary, J. P. and S. J. G. van Wijnbergen (1986). Natural Resources and the Macroeconomy. MIT Press, Cambridge, MA.

Pedroni, P. (2007). Social Capital, Barriers to Production and Capital Shares: Implications for the Importance of Parameter Heterogeneity from a Nonstationary Panel Approach. Journal of Applied Econometrics 22, 429-451.

Pesaran, M. and B. Pesaran (2009). Microfit 5.0: An Interactive Econometric Software Package. Oxford University Press, Oxford.

Pesaran, M. H. (1982). The System of Dependent Capitalism in Pre- and PostRevolutionary Iran. International Journal of Middle East Studies 14(4), 501-522.

Pesaran, M. H. and Y. Shin (1996). Cointegration and Speed of Convergence to Equilibrium. Journal of Econometrics 71, 117-143.

Pesaran, M. H. and Y. Shin (1998). Generalised Impulse Response Analysis in Linear Multivariate Models. Economics Letters 58, 17-29. 
Pesaran, M. H., Y. Shin, and R. J. Smith (2000). Structural Analysis of Vector Error Correction Models with Exogenous I(1) Variables. Journal of Econometrics 97, 293-343.

Sachs, J. D. and A. M. Warner (1995). Natural Resource Abundance and Economic Growth. National Bureau of Economic Research Working Paper 5398.

Sims, C. (1980). Macroeconomics and Reality. Econometrica 48, 1-48.

Tornell, A. and P. R. Lane (1999). The Voracity Effect. The American Economic Review 89(1), 22-46.

van der Ploeg, F. and T. Venables (2009). Symposium on Resource Rich Economies Introduction. Oxford Economic Papers 61(4), 625-627. 